\title{
School efficiency and student development: Is good school suitable for every student in Vietnam?
}

\author{
Lan Thi Ngoc Nguyen ${ }^{a *}$, Hanh Phuc Le ${ }^{\mathrm{b}}$, Thach Thao Than ${ }^{\mathrm{b}}$, Viet Ha Ho ${ }^{\mathrm{c}}$ and Giang Nguyen ${ }^{\mathrm{d}}$
}

${ }^{a}$ School of Economics, Finance and Management, The University of Bristol or School of Accounting and Auditing, Van Lang University, Vietnam ${ }^{b}$ School of Advanced Education Programs, National Economics University, Vietnam

${ }^{c}$ Business School, National Economics University, Vietnam

IInternational Business, Faculty of Business, FPT University, Hanoi, 100000, Vietnam

\section{H R O N I C L E}

\section{Article history:}

Received: June 26, 2020

Received in revised format:

June 302020

Accepted: July 22, 2020

Available online:

September 24, 2020

Keywords:

Quality Function Deployment

School training

Vietnam

\section{A B S T R A C T}

This research aims to investigate the impact of school efficiency on student development and sheds light on the way that top-universities enhance students' knowledge, skills, health, and psychological development. Through interviewing and sending online questionnaires to over 2000 students from 5 top universities in Vietnam based on Ranking Web of Universities, the research results suggest the significant influence of school-related factors, student demographic factors, and students' personality on student development. Specifically, teaching quality has a positive relationship with all dependent variables except for psychosocial development. The results also illustrate that school facilities positively relate to students' satisfaction but negatively associate with their academic performance. Additionally, the research points out that boys have better psychological, mental, and physical development than girls do. At the same time, students with lower schoolyear tend to have a higher level of studying satisfaction. Furthermore, the impact of personality, including openness, conscientiousness, and extraversion, on student development is remarkable due to their significant positive connections with all five dependent variables. On the other hand, agreeable students appear to have less psychological development than those in other personality groups.

\section{Introduction}

Improving students' competencies creates a massive advantage for the labor market, influencing the national development since students are vital human capital quality (Bjorke, 2017). During the last twenty centuries, training high-quality human resources to meet the market demands is an irreplaceable task for a nation due to the international economic integration process (Aljaaidis et al., 2020). Since then, governments have taken their concentration on improving national educational systems through universities' budgets and other student administration and support services. Universities take enormous responsibility for this commission because universities' objectives are to educate and equip students with necessary skills and technical knowledge before they integrate into the working environment (Idrisa et al., 2012; Ahmad \& Szpara, 2005).

Besides, acquiring general knowledge and practical experiences, students should arm themselves with variously specialized, interpersonal skills and health improvement to develop comprehensively. Many researchers have emphasized the importance of interpersonal skills; as such, these skills contribute $85 \%$ to the success of a worker, while the remaining $15 \%$ is made up of hard skills. Many evidence pointing out a lack of conscious awareness in improving these skills among students from tertiary education institutions has been found (Porter, 2007; Rynes, et al., 2003; Banks, 2014), resulting in the shortages of working competencies in employers' demands. Notably, the British Association of Graduate Recruiters recently has confirmed that while students usually are academically proficient, a considerable deficiency of soft skills such as teamwork, communication, and critical reasoning is arising gradually among different graduate candidates. 
Another current alarming issue in student development is health status, including physical and mental health (Harafsheh, et al., 2020). "We are facing a national mental health crisis, and college campuses are reflecting what's going on in society at large," said Dr. Victor Schwartz, a chief medical officer of the Jed Foundation in an interview with ABC News. This problem is reflected more clearly in the suicide rate of college students between the ages of 18 and 24 . Approximately 1,100 and nearly 24,000 people attempt suicide every year in the United (Coleman, 1966; Ewell, 2005). Hence, it is clear that student development is encountering many concerning troubles. Overtime, four different disciplines related to student development are formed, they are Psychological, Cognitive \& Moral, Typology, Person-Environment. Psychologists define the development in terms of the consequences of changes in emotions, thoughts, and values affecting individuals and others (Chickering \& Reisser, 1993). Different from psychology, the second discipline is related to the intellectual, cognitive, and virtuous enhancement (Kohlberg, 1958). The third theoretical line takes concentration on the students' intentions of learning and their attributions to society (Bloom, 1956). Finally, the person-environment thesis examines the relationship between surrounding learning environments and students (Sandeen, 1991). In this paper, we will follow the typology approach because it takes into account a complete set of measures as opposed to other approaches in evaluating student development.

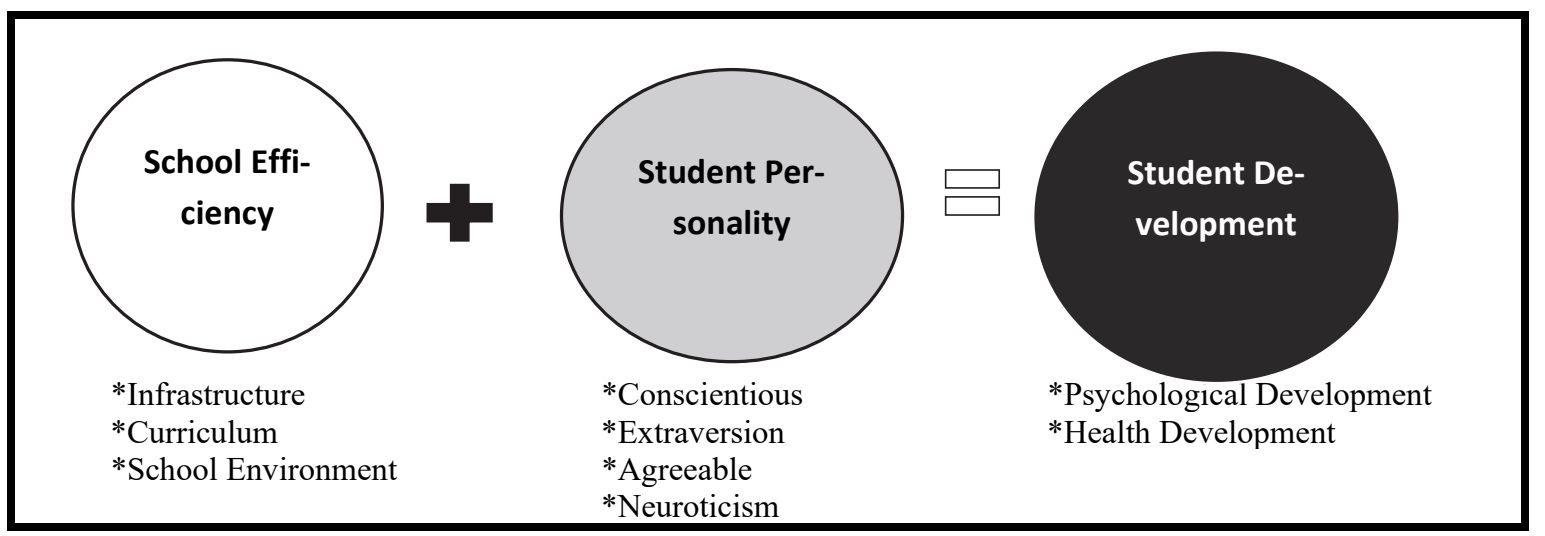

Fig. 1. Student Development

Through interviewing and sending online questionnaires to over 2000 students from 5 top universities in Vietnam based on Ranking Web of Universities, our research results suggest the significant influence of school-related factors, student demographic factors, and students' personality on student development. Specifically, teaching quality has a positive relationship with all dependent variables except for psychosocial development. The results also illustrate that school facilities positively relate to students' satisfaction but negatively associate with their academic performance. Additionally, the research points out that boys have better psychological, mental, and physical development than girls. At the same time, students with lower schoolyear tend to have a higher level of studying satisfaction. Furthermore, the impact of personality, including openness, conscientiousness, and extraversion, on student development is remarkable due to their significant positive connections with all five dependent variables. On the other hand, agreeable students appear to have less psychological development than those in other personality groups.

\section{Literature review}

Human resources play a crucial part in all aspects of national development; consequently, prioritizing human development can help a country bring a more sustainable and prosperous future for its citizens (Lonska \& Mietule, 2015). The Government always takes a high concentration on education by providing funds for primary and secondary education. The reason is that the national economy becomes more productive if the proportion of educated workers who can efficiently carry out tasks that require literacy and critical thinking increases (Hanushek \& Woessmann, 2008). Hence, it confirms the inevitable status of school efficiency and student development since they are the most critical intellectual resources of society, contributing to national excellence. Student development theory depicts students in their changes, growth, and progress (Walker, 2008). In other words, it can be defined as the accumulation of knowledge, self-development, and initial acquirement of experience the way they learn how to learn (Duque \& Weeks, 2010). Although there are many different models of student development, the basic premise is still the same. Student development reflects on humans' growth under the influences of in-class and outclass activities. According to Walker (2008), the most often used typology theory is Bloom's taxonomy about learning objectives, including cognitive, affective (psychological), and psychomotor domain. From Posner's (1992) point of view, cognitive development is the accumulation of knowledge and the advancement of thinking. For knowledge assessment, since all course results are in academic transcripts, GPA is considered a reliable index. Besides, language comprehension, office computer proficiency are some common indicators of essential soft skills that students would aim themselves. In term of psychology, Gatten (2004) conceptualized psychological development as the improvement of identity, interpersonal circle, and the psychology usually evaluated by communication skills, personal initiative, motivation or interpersonal skills (Duque 
\& Weeks, 2010; Gudeva et al., 2012; Vanwynsberghe et al., 2017). Finally, the psychomotor domain contains manual or physical skills, which are no longer as important in everyday life and work as before since both academics and practitioners do not take technical skills seriously in the context of automation. In this research, we add health comprising physical health and mental health as the fourth aspect that Bloom left out in his model to comprehend the measurement of student development. It is due to numerous studies have revealed a correlation between students' well-being and development and found that stress adversely influences performance outcomes (Sanders \& Lushington, 2002). Furthermore, more and more students have faced mental and physical health problems, which could limit their motivations and ability to develop during college years due to a significant rise in workload and parents' expectations (Sanders \& Lushington, 2002; Wilks et al., 2020).

About the effectiveness of universities, it is no doubt that universities are one of the most crucial driver factors shaping student development. Technical efficiency refers to the maximization of possible outcomes produced at a given level of the inputs (Palmer \& Torgerson, 1999; Phuc, et al., 2020). At an educational institute, researchers have reached a consensus that the educational outcomes are student developments, (Agasisti \& Zoido, 2019; Guironnet \& Peypoch, 2017), skill enhancement (Conard, 2006; Podinovski et al., 2014; Queiroz et al., 2019) and psychosocial development (Kirjavainen, 2009). Educational inputs, on the other hand, are hard to measure, since they are related to several qualitative perspectives such as family background factors and school-related factors. The former comprises parents' educational background and socioeconomic class, and the later include teacher quality, non-academic staff, and school curriculum. A significant concern has been raised about whether family background should be involved in the student input. While Guironnet and Peypoch (2017), Podinovski et al. (2014) and Queiroz et al. (2019) point out that family background is an essential factor beside school factors affecting students' outputs, other researchers reject family elements. This is because they argue that family-related factors are personal components that are not applicable in assessing the efficiency of the universities (Abbott \& Doucouliagos, 2003; Agasisti \& Zoido, 2019). The purpose of the paper is to assess the impact of schools on students and we follow the second opinion, which concerns only the school factors.

In order to assess the concern of whether a good university is suitable for every type of student, we then add the students' personality as one of the control variables in our model (Appelbaum, 2006). This is because personality is one of the most critical competencies affecting individuals' intellectual and psychological development (Chamorro-Premuzic \& Furnham, 2003; Vasileva-Stojanovska et al., 2015). According to Komarraju et al. (2011), a correlation between personality and academic performance does exist but depends on character types; it is either positive or negative. By using the OCEAN personality model first developed by McCrae and John in 1992, Komarraju et al. (2011) debate that with a different personality, individuals would their strengths and weakness, leading to different academic and practical outcomes. Specifically, personality divides into five different groups: openness, conscientiousness, agreeableness, extraversion, and neuroticism. Empirically and theoretically speaking, extraversion and conscientiousness achieve higher academic results than other characteristics (Kim, Kwon, \& Cho, 2011). This is because introvert groups have better-focusing ability in class and more effective learning methods than extrovert groups (Hakimi, Hejazi, \& Lavasani, 2011). Specifically, conscientious students have the best self-study capability and, therefore, is the most excellent academic achievers among five personality groups (Koning et al., 2012). By contrast, neuroticism group often lacks motivations for book learning, resulting in poor studying performance (Zee, Koomen, \& Veen, 2013). That because of a higher level of stress and a lack of confidence, which weakens their learning ability. Similarly, extraversion students do not have good results in class; however, they more actively engage in social relationships with teachers and friends than neurotic students (Zee et al., 2013).

\section{Hypotheses and empirical models}

\subsection{Hypothesis}

The study aims to determine and evaluate the impact of 5 different independent variables displayed in the models by raising five research hypotheses below:

H1: Academic staffs are positively correlated with student development.

The correlation of academic staff with students can be determined by examining the qualifications, experience, awareness, and accessibility of teachers. Harris \& Sass (2010) indicate that teacher effectiveness enormously contributes to student development in terms of cognitive and psychosocial development due to frequent interactions between them (Kaplan \& Owings, 2001). Stronge et al. (2007) show that teachers with strong academic backgrounds tend to enhance student performance at school, while those with weaker qualifications may have an adverse effect on students' outcomes. It is reasonable because teachers with a more profound understanding and stimulating teaching methods can precisely convey their knowledge to students and answer their confusion. Additionally, class practices provided by teachers significantly boost students' motivation and improve students' soft skills (Goe \& Stickles, 2008). As a result, class activities, such as teamwork and outdoor learning activities, can help students accomplish both knowledge and generic skills by interacting and working with others on the given tasks.

$\mathbf{H}_{2}$ : Infrastructure is positively associated with student development.

The relationship between infrastructure and student development can be tested by the quality of school facilities, including the library, classroom, computer lab, health care center, and demonstration rooms. School facilities are one of the most crucial 
factors affecting the academic outcomes since they can equip students with the best learning conditions before enhancing students' performance. School condition, in fact, directly correlates with health issues (Earthman \& Lemasters, 1996) since the supporting facilities, such as gym centers and healthcare services at schools, can boost student mental and physical wellbeing. By contrast, poor school infrastructure, such as broken toilets, or unsanitary canteen, negatively influences students' comfort (Duran-Narucki, 2008). Therefore, it can be said that the relationship between infrastructure and cognitive development, as well as student's health, is positive.

H3: Curriculum has a positive effect on student development.

The impact of teaching curriculum on student development can be determined by evaluating the quality, efficiency, attractiveness, and availability of study materials, along with the suitability of the studying timetable. Kuh et al. (2006) illustrate the importance of the school curriculum to student achievement; notably, this factor decides whether students have opportunities to easily approach reliable and updated academic resources, thereby helping them better perform at school (Katula \& Threnhauser, 1999). Kuh et al. (2006) also mention the cruciality of the efficient school curriculum to determine the students' outcomes since if school lessons are appealing but impractical, students will not know how to use it. Besides, according to (Kain et al., 2017), a suitable timetable can bring a constructive effect on student development since it not only can make the course logical and workable but also can improve student strength and reduce studying stress. As a result, student development positively links to the school curriculum.

H4: School environment has a positive effect on student development.

By looking at school extracurricular and class activities, we can examine the impact of the school environment on student development. Wechsler et al. (2000) emphasize the significant contribution of the teaching environment to cognitive development, psychosocial development, and the health improvement of students. In terms of class activities, students, especially the active ones, can acquire both knowledge and interpersonal skills because they must interact with one another during the events (Leeming et al., 1997; Choi, 2005). Additionally, Cooper et al. (1999) show that extracurricular activities can strengthen both the mental and physical health of students as they can explore and learn new life lessons and skills beyond books, which balances both their academic and social life. Consequently, the school environment is one of the critical factors for students to achieve a complete development.

H5: Personalities have significant effects on student development.

Personalities are also a pivotal element of student development since each person has their individual experiences and motivations of being developed. There are five types of characters, including openness, conscientiousness, agreeableness, neuroticism, and extraversion, based on Big Five Personality Traits (Costa \& Mccrae, 1992). As mention above, students can barely experience similar improvements in terms of cognitive development, psychosocial development, and health in the same circumstance and academic environment. According to Costa \& Mccrae (1992) and Patrick (2011), each group of 5 traits results in different kinds of student behaviors and performance at school. Particularly, openness, agreeableness, conscientiousness, and extraversion have positive relationships with academic performance. Contrastly, neuroticism adversely influences student achievement (Komarraju et al., 2011; Bafadal, 2003). We will conduct models to determine whether these five personalities cause different or even contradictory impacts on students under one similar learning condition.

\subsection{Empirical models}

Quantitative research is a prevalent method in our research to clarify the impact of 5 independent variables (academic staff, infrastructure, curriculum, school environment, and personalities) on three variables (cognitive development, psychosocial development, and health). We build regression models and take advantage of both SPSS 22 and STATA 2016 in analyzing these models. Three following models to measure four dependent variables can be built as follow:

Model 1: $K N O=\alpha+\beta_{1} \times A C A+\beta_{2} \times I N F+\beta_{3} \times C U R+\beta_{4} \times E N V+\beta_{5} \times D_{1}+\beta_{6} \times D_{2}+\beta_{7} \times D_{3}+\beta_{8} \times D_{4}+\varepsilon$,

Model 2: $S K I=\alpha+\beta_{1} \times A C A+\beta_{2} \times I N F+\beta_{3} \times C U R+\beta_{4} \times E N V+\beta_{5} \times D_{1}+\beta_{6} \times D_{2}+\beta_{7} \times D_{3}+\beta_{8} \times D_{4}+\varepsilon$

Model 3: $P S Y=\alpha+\beta_{1} \times A C A+\beta_{2} \times I N F+\beta_{3} \times C U R+\beta_{4} \times E N V+\beta_{5} \times D_{1}+\beta_{6} \times D_{2}+\beta_{7} \times D_{3}+\beta_{8} \times D_{4}+\varepsilon$,

Model 4: $H E A=\alpha+\beta_{1} \times A C A+\beta_{2} \times I N F+\beta_{3} \times C U R+\beta_{4} \times E N V+\beta_{5} \times D_{1}+\beta_{6} \times D_{2}+\beta_{7} \times D_{3}+\beta_{8} \times D_{4}+\varepsilon$,

where: $\alpha, \beta_{1}, \beta_{2}, \beta_{3}, \beta_{4}, \beta_{5}, \beta_{6}, \beta_{7}$, and $\beta_{8}$ are coefficients, $D_{1}, D_{2}, D_{3}, D_{4}$ are dummy variables presenting five different personalities, $\varepsilon$ is error.

Table 1 below illustrates the meaning and the role of both dependent variables and independent variables. 
Table 1

List of dependents and independent variables of the regression models

\begin{tabular}{|c|c|c|c|c|c|}
\hline Variables & & Meaning & Determined by & Role & Model \\
\hline \multirow{3}{*}{$\mathrm{COG}$} & $\mathrm{KNO}$ & Knowledge & GPA & Dependent variable & COG1 \\
\hline & \multirow{2}{*}{ SKI } & \multirow{2}{*}{ Skill } & IT & Dependent variable & COG2 \\
\hline & & & Language & Dependent variable & COG3 \\
\hline \multirow{4}{*}{ PSY } & & \multirow{4}{*}{ Psychosocial } & Communication & Dependent variable & PSY1 \\
\hline & & & Teamwork & Dependent variable & PSY2 \\
\hline & & & Motivation & Dependent variable & PSY3 \\
\hline & & & Interpersonal skills & Dependent variable & PSY4 \\
\hline \multirow{2}{*}{ HEA } & & \multirow{2}{*}{ Health } & Mental health & Dependent variable & HEA1 \\
\hline & & & Physical health & Dependent variable & HEA2 \\
\hline \multirow{5}{*}{$\mathrm{ACA}$} & & \multirow{5}{*}{ Academic Staffs } & Qualifications & Independent variable & ACA1 \\
\hline & & & Evaluation fairness & Independent variable & ACA2 \\
\hline & & & Teacher practices & Independent variable & $\mathrm{ACA} 3$ \\
\hline & & & Teachers' awareness & Independent variable & ACA4 \\
\hline & & & Teachers' accessibility & Independent variable & ACA5 \\
\hline \multirow{6}{*}{ INF } & & \multirow{6}{*}{ Infrastructure } & Health services & Independent variable & INF1 \\
\hline & & & Sanitation & Independent variable & INF3 \\
\hline & & & Library and learning resource center & Independent variable & INF4 \\
\hline & & & Lecture room/ classroom & Independent variable & INF5 \\
\hline & & & Computer lab & Independent variable & INF6 \\
\hline & & & Demonstration rooms and skills lab & Independent variable & INF7 \\
\hline \multirow{5}{*}{ CUR } & & \multirow{5}{*}{ Curriculum } & Qualitied materials & Independent variable & CUR1 \\
\hline & & & Efficient materials & Independent variable & CUR2 \\
\hline & & & Attractive materials & Independent variable & CUR3 \\
\hline & & & Information availability & Independent variable & CUR4 \\
\hline & & & Timetable & Independent variable & CUR5 \\
\hline \multirow{4}{*}{ ENV } & & \multirow{4}{*}{ School Environment } & Vocational activities & Independent variable & ENV1 \\
\hline & & & Entertainment & Independent variable & ENV2 \\
\hline & & & Peer attitude & Independent variable & ENV3 \\
\hline & & & Extracurricular & Independent variable & ENV4 \\
\hline \multirow{5}{*}{ PER } & & \multirow{5}{*}{ Personality } & Openness & Independent variable & PER1 \\
\hline & & & Conscientious & Independent variable & PER2 \\
\hline & & & Agreeable & Independent variable & PER3 \\
\hline & & & Neuroticism & Independent variable & PER4 \\
\hline & & & Extraversion & Independent variable & PER5 \\
\hline
\end{tabular}

\subsection{Research methodology}

In this research, with an intention to have an accurate and appropriate judgment of students' progress, it is necessary to evaluate student development through both cognitive and psychological development, and through a thorough consideration of their health issues (Nusche, 2008).

Research Time Period: The research is conducted from January to April 2020, which is the time that college students in Vietnam off school during the Lunar New Year holiday. For this reason, they are in a stable condition of mental health with a minimum of stress and tiredness during the courses. Moreover, the physical health of students also has been improved because they do not need to work hard to finish schoolwork, and they can eat in moderation with nourishing meals.

The Research Data: Research data were collected by randomly giving questionnaires to more than 400 students per chosen university, including freshman, sophomore, junior, senior, and graduate. Moreover, students attending our survey come from numerous faculties, institutes, or majors to make sure that the collected data is reliable, transparent, and accurate.

With in-depth online interviews and 2000 online questionnaires given out at five different universities, we conducted 1374 observations to get the best estimate. On that basis, we set up three regression models for analysis and verification with the help of specialized software such as SPSS 22 and STATA version 2016.

Table 2

Research observations

\begin{tabular}{|c|c|c|c|c|c|c|}
\hline & Freshman & Sophomore & Junior & Senior & Graduate & Total \\
\hline Hanoi University of Science and Technology (HUST) & 94 & 158 & 33 & 33 & 24 & 342 \\
\hline National Economics University (NEU) & 85 & 101 & 41 & 6 & 5 & 238 \\
\hline Foreign Trade University (FTU) & 135 & 68 & 20 & 13 & 14 & 250 \\
\hline Ho Chi Minh City Medicine and Pharmacy University (YDS) & 109 & 38 & 4 & 23 & 38 & 212 \\
\hline Hanoi Medical University (HMU) & 58 & 47 & 53 & 52 & 95 & 305 \\
\hline Total & 481 & 412 & 151 & 127 & 176 & 1347 \\
\hline
\end{tabular}


We have surveyed in three different school categories, including economics, science and technology, and medicine in the top five best universities in Vietnam based on Ranking Web of Universities, including Ho Chi Minh City Medicine and Pharmacy University (YDS), Hanoi Medical University (HMU), Hanoi University of Science and Technology (HUST), Foreign Trade University (FTU), and National Economics University (NEU). We randomly selected 400 students, including freshman, sophomore, senior, and graduate from each chosen university to collect opinions from different faculties. To verify the research statement that whether a good school is suitable for every student, we believe that these five schools are one of the best options mainly because those are leading schools with high ranking in each field in Vietnam.

\section{Results}

\subsection{Reliable analysis using Cronbach's Alpha test}

The reliable analysis based on Cronbach's Alpha test shows that all independent variables comprising ACA, CUR, INF, and ENV have an appropriate total correlation coefficient with Cronbach's Alpha coefficient $\geq 0.8$. Specifically, Cronbach's Alpha of ACA equals 0.823, showing that ACA1, ACA2, ACA3, ACA4, and ACA5 meet the requirements of reliability, and these measures can represent the scale of ACA very well. The total correlation coefficient of CUR is $0.877 \geq 0.8$, which implies that CUR1, CUR2, CUR3, CUR4, and CUR5 satisfy the reliability requirement and can measure the scale of CUR precisely. The Cronbach's Alpha coefficient of INF variables is reliable $(0.902 \geq 0.8)$, which means that the measurement of INF1, INF2, INF3, and INF4 on INF is suitable. These outcomes for ENV are similar to those of INF when the Cronbach's Alpha coefficient equals $0.83(\geq 0.8)$. This indicates that ENV1, ENV2, ENV3, and ENV4 fulfill the requirement of reliability and can measure the scale of ENV very strongly. At the same time, the Cronbach's Alpha coefficient of PSY with a value of 0.48 is qualified enough to conduct this research.

\subsection{EFA test}

The discovery factors EFA test reveals $0.5<\mathrm{KMO}$ coefficient $=0.954<1.000$, therefore concluding that the variables are consistent with the research. Additionally, the value of Sig (Bartlett's Test of Sphericity) is equal to $0<0.05$, indicating that variables correlated with one another. With the Eigenvalues at $1.086>1$, we can extract the three most reliable components for this study. Correspondently, we exclude the fourth component as it is equal to 0.772 , while the Eigenvalues must be higher than 1 . The percentage of variance is $63,306 \%>50 \%$ that means the observation accounts for $63,306 \%$ of variabilities referring to the model appropriateness. After conducting a reliable analysis with Cronbach's Alpha test and EFA test, we do the following table to show the remaining variables in the models.

\section{Table 3}

Remaining variables in the model

\begin{tabular}{llll}
\hline \multicolumn{1}{c}{ No. } & \multicolumn{1}{c}{ Name } & \multicolumn{1}{c}{ Remaining measures } & Meaning \\
\hline 1 & COG & GPA, IT, Language & Cognitive development \\
2 & PSY & Communication, Teamwork, Motivation, Interpersonal skills & Psychological development \\
3 & HEA & Mental health, Physical health & Health development \\
4 & QUA & CUR1, CUR2, CUR3, CUR4, CUR5, ACA1, ACA2 & Teaching quality \\
5 & FAC & INF1, INF2, INF3, INF4, INF5, INF6, ENV1 & Facilities and Infrastructures \\
6 & ENT & ACA1, ENV4, ENV2, ACA5 & Teaching environment \\
\hline
\end{tabular}

\subsection{Descriptive analysis}

Fig. 2 compares four independent variables, including academic staff, curriculum, infrastructure, and school environment from five high-ranking schools in Vietnam (Ho Chi Minh City Medicine and Pharmacy University-YDS, Hanoi Medical University-HMU, Hanoi University of Science and Technology-HUST, Foreign Trade University-FTU, and National Economics University-NEU). Overall, it is clear that NEU has the most positive response in three out of four elements except for the school curriculum, which is leading by YDS. In contrast, FTU receives the least positive feedback from students about its curriculum and infrastructure, at the same time, HMU students assume that their school does not offer pleasant academic staff and school environment for them.

Noticeably, school environments are varied among the three different fields among five schools. Economics universities tend to have higher values in ENV with 3.63 in NEU and 3.58 in FTU; on the contrary, science-technological, and medical schools demonstrate smaller numbers with 3.4 in HUST, 3.47 in YDS, and 3.3 in HMU. The quality of the facilities in each university is considerably different as well. The NEU infrastructure value is the highest in the chart (3.9), slightly higher than that of YDS (3.87), and 0.4 units above that of FTU. Concerning curriculum, FTU remains the lowest at 3.32, while YDS is the highest at 3.51, slightly higher than that of HMU (3.48), NEU (3.47), and HUST (3.45). In terms of academic staff, there is no significant difference among them as all five universities were ranked around 3.4. Fig. 3 analyzes three dependent variables, including cognitive (GPA, IT, Language), psychosocial, and health development from five top universities in Vietnam, including Ho Chi Minh City Medicine and Pharmacy University (YDS), Hanoi Medical University (HMU), Hanoi University of Science and Technology (HUST), Foreign Trade University (FTU), and National Economics University (NEU). 


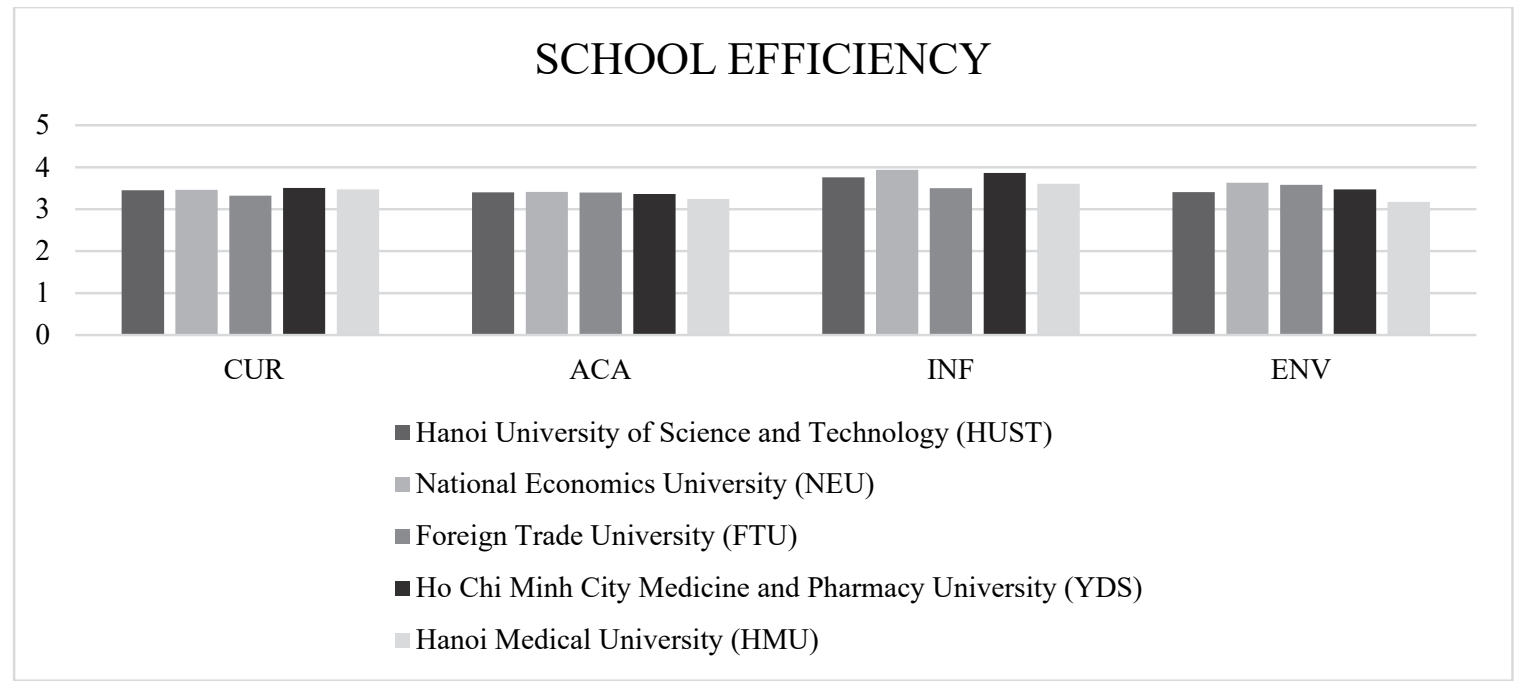

Fig. 2. Independent variables of 5 universities

Overall, in all three indicators of COG (GPA, IT, Language), economics schools received the best responses. Still, in terms of PSY and HEA, the variation amongst five universities is not remarkable. Regarding COG, the GPA of YDS students with 2.37 units is the lowest, while FTU with 3.62 units is the highest in the chart. FTU $(2,46)$ remains the highest among five universities in the area of language, while NEU, HMU, YDS, and HUST reach 2.32, 2.45, 2.25, and 2.18, respectively. In terms of IT skills, NEU is leading in the graph with 2.66 units, followed by YDS (2.59), HUST (2.5), FTU (2.496), and HMU (2.45). For PSY, although FTU is the highest with 3.7 units, the variation of the other four universities is not much significance as they are all around 3.6. Likewise, all of the surveyed universities showed that their students' health is comparatively the same because the given results are all around 3.3 units

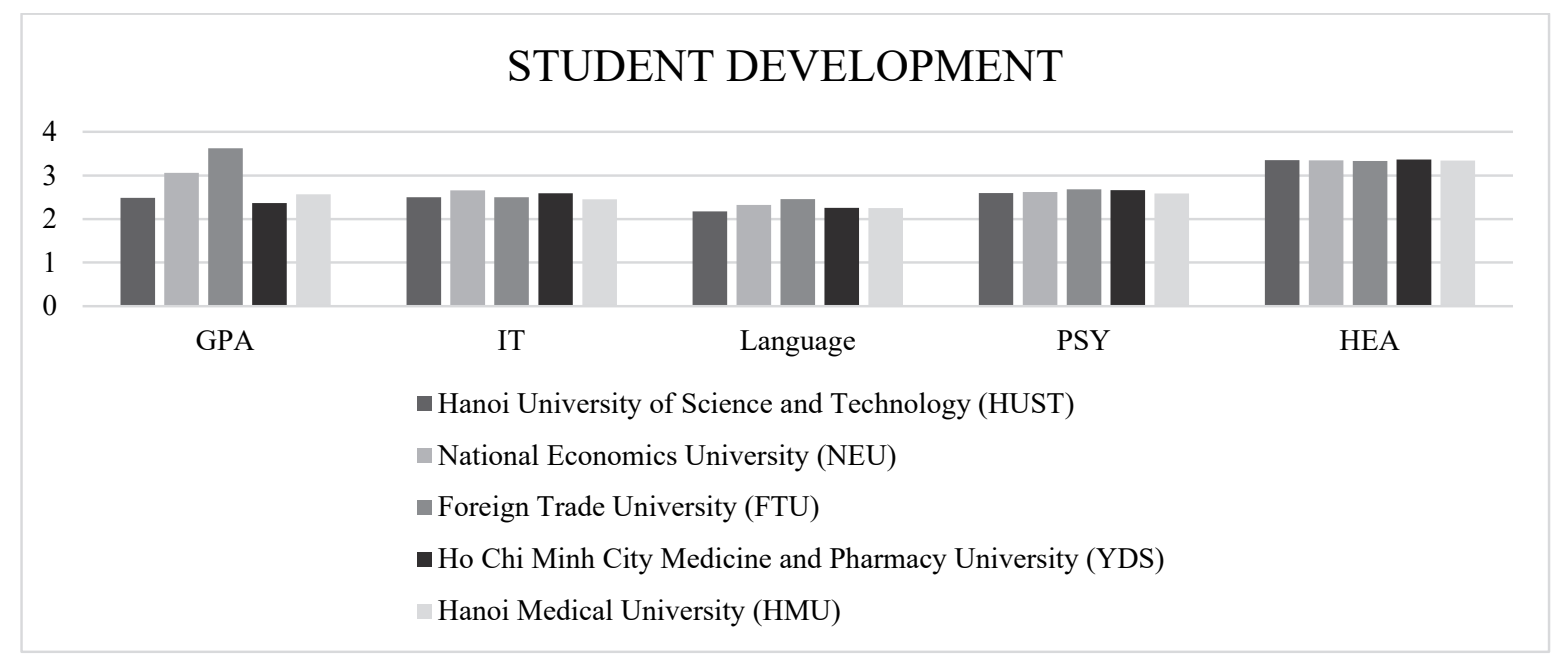

Fig. 3. Dependent variables of 5 universities

\subsection{Correlation analysis}

We test the correlation among variables in the models based on SPSS's results in the five most prestigious Vietnamese universities: Hanoi University of Technology and Science, National Economics University, Foreign Trade University, Ho Chi Minh City Medicine and Pharmacy University, and Hanoi Medical University. It can be said that all dependent variables experience low levels of correlations with each other. Meanwhile, the independent correlations go through all types of correlations comprising no correlation, weak correlation, and strong one. If the two-independent-variables correlation has $r>0.4$ and sig. $<0.05$, there is a possibility of the occurrence of the multi-collinear phenomenon. We will examine whether or not this phenomenon can happen at the next stages. About KNO, it is significantly affected by QUA and ENT, while SKI has two positive correlations with QUA and Extraversion. All characteristic variables except for conscientious influence PSY, while school-related factors do not impact PSY. Openness and extraversion positively correlate to PSY; however, agreeable has a negative impact on PSY dependent variable at $\mathrm{r}=-0.198$ and sig. $=.000$. In terms of HEA, all independent variables 
have positive impacts on it, and QUA has the strongest correlation with HEA. About the last dependent factor, Satisfaction is positively impacted by school elements, including QUA, FAC, ENT, so enhancing school quality will raise students' satisfaction. And no personalities except for Openness have correlations with Satisfaction.

\subsection{Regression analysis}

Table 4 illustrates the regression analysis results for four main dependent variables, which are KNO (model 1a) and SKI (model 1b), represented for cognitive development, PSY (model 2) described for psychological development, and HEA (model 3) represented for health development. In addition to four main dependent variables, we add another dependent variable measuring the level of students' satisfaction SAT (model 4) in studying at their university. Overall, with the statistical significance of $90 \%$, it can be said that the changes in KNO, SKI, PSY, HEA, and satisfaction can be explained 3\%, 9.94\%, $10.9 \%, 8.53 \%, 15.3 \%$, and $41.2 \%$ respectively by the variations in school-related variables, student demographic variables, and students' personality variables. FAC positively correlated with satisfaction but negatively associated with KNO, while QUA positively impacts all five dependent variables expected for PSY. Regarding ENT, a significant positive correlation can be found between ENT and two dependent variables measuring students' knowledge and their satisfaction on higher education. However, at the confidence level of $99 \%$, it can be said that ENT also negatively impacts both SKI and PSY. SEX and YEA are two control variables accounting for the impact of sexuality and schooling years on student development. A significantly positive association can be found between SEX and PSY, SEX, and HEA, but a significantly negative relationship exists between YEA and Satisfaction. This would mean that while boys have better psychological, mental, and physical development than girls, those in lower schoolyear have a higher level of studying satisfaction. The impact of personality on student development is conservable and remarkable, especially openness, conscientious, and extraversion since all these variables make up a statistical significance with all five dependent variables with the confidence level of at least $90 \%$. Specifically, students who are open, conscientious, or extraversion will have significantly better knowledge, skills, psychological characteristics, health, and satisfaction and those with other personalities. By contrast, agreeable students seem to have more inadequate mental development that those in other personality groups.

Table 4

$\underline{\text { Regression analysis }}$

\begin{tabular}{|c|c|c|c|c|c|}
\hline & (1a) & (1b) & (2) & (3) & (4) \\
\hline VARIABLES & $\mathrm{KNO}$ & SKI & PSY & HEA & Satisfaction \\
\hline \multirow[t]{2}{*}{ FAC } & $-0.171 * * *$ & 0.0108 & 0.00830 & -0.00912 & $0.0506^{* * *}$ \\
\hline & $(0.0540)$ & $(0.0352)$ & $(0.0302)$ & $(0.0296)$ & $(0.0168)$ \\
\hline \multirow[t]{2}{*}{ QUA } & $0.114^{*}$ & $0.114 * * *$ & 0.0546 & $0.104 * * *$ & $0.0315^{*}$ \\
\hline & $(0.0615)$ & $(0.0401)$ & $(0.0344)$ & $(0.0337)$ & $(0.0191)$ \\
\hline \multirow[t]{2}{*}{ ENT } & $0.156 * * *$ & $-0.0814 * * *$ & $-0.0580 * *$ & 0.00567 & $0.0429 * * *$ \\
\hline & $(0.0478)$ & $(0.0311)$ & $(0.0267)$ & $(0.0262)$ & $(0.0148)$ \\
\hline \multirow[t]{2}{*}{ SEX } & -0.0944 & 0.0370 & $0.0995 * * *$ & $0.132 * * *$ & -0.00455 \\
\hline & $(0.0585)$ & $(0.0381)$ & $(0.0327)$ & $(0.0321)$ & $(0.0181)$ \\
\hline \multirow[t]{2}{*}{ YEA } & -0.0301 & 0.0176 & -0.0120 & -0.00736 & $-0.0139 * *$ \\
\hline & $(0.0195)$ & $(0.0127)$ & (0.0109) & $(0.0107)$ & $(0.00605)$ \\
\hline \multirow[t]{2}{*}{ Openness } & $0.239 * * *$ & $0.108 *$ & $0.331 * * *$ & $0.455 * * *$ & $0.131 * * *$ \\
\hline & $(0.0857)$ & $(0.0558)$ & $(0.0479)$ & $(0.0470)$ & $(0.0266)$ \\
\hline \multirow[t]{2}{*}{ Conscientious } & $0.224 * * *$ & $0.113^{* *}$ & $0.149 * * *$ & $0.406 * * *$ & $0.109 * * *$ \\
\hline & $(0.0826)$ & $(0.0538)$ & $(0.0462)$ & $(0.0453)$ & $(0.0256)$ \\
\hline \multirow[t]{2}{*}{ Agreeable } & 0.0760 & 0.0197 & $-0.0671 *$ & $0.478 * * *$ & $0.0936^{* * *}$ \\
\hline & $(0.0728)$ & $(0.0474)$ & $(0.0407)$ & (0.0399) & $(0.0226)$ \\
\hline \multirow[t]{2}{*}{ Extraversion } & $0.195^{* *}$ & $0.226^{* * *}$ & $0.423 * * *$ & $0.422 * * *$ & $0.0512 *$ \\
\hline & $(0.0960)$ & $(0.0625)$ & $(0.0537)$ & $(0.0527)$ & $(0.0298)$ \\
\hline \multirow[t]{2}{*}{ Constant } & $2.516 * * *$ & $2.097 * * *$ & $2.473 * * *$ & $2.636 * * *$ & $0.412 * * *$ \\
\hline & $(0.153)$ & $(0.0994)$ & $(0.0853)$ & $(0.0837)$ & $(0.0473)$ \\
\hline Observations & 1,347 & 1,347 & 1,347 & 1,347 & 1,347 \\
\hline R-squared & 0.030 & 0.029 & 0.109 & 0.153 & 0.103 \\
\hline
\end{tabular}

Standard errors in parentheses

$* * * \mathrm{p}<0.01, * * \mathrm{p}<0.05, * \mathrm{p}<0.1$

In model 1, QUA significantly and positively is correlated with both KNO and SKI, whereas ENT negative effects on SKI but positively associates with KNO. FAC has a negative and significant impact on KNO but has no relationship with SKI with a confidence level of 95\%. Regarding the student's demographic factors, including gender (SEX) and learning year (YEA), 
both of these control variables seem to be not relevant to academic performance at the statistical significance of $95 \%$. Interestingly, the relationship between personality and cognitive development is remarkable when students who are open, conscientious, or extraverted seem to have better KNO and SKI than those with other personalities since the estimated coefficient of these control variables are all positive. Particularly, open students are observed to achieve 0.239 out of 5 units higher than ones without this character. Correspondingly, those with conscientious and extraversion are likely to get a better GPA of 0.334 and 0.195 out of 5 units, respectively. Model $1 \mathrm{~b}$ also points out that students with conscientious and extraversion characters can achieve 0,113 and 0,226 points higher than those without these characters in terms of these academic skills. Thus, model $1 \mathrm{a}$ and $1 \mathrm{~b}$ can be written as below:

\section{COG Model:}

Model 1a: $K N O=2.516-0.171 \times F A C+0.114 \times Q U A+0.156 \times E N T+0.239 \times$ Openness $+0.224 \times$ Conscientious $+0.195 \times$ Extraversion $+\mu$

Model 1b: SKI $=2.097+0.114 \times Q U A-0.0814 \times$ ENT $+0.108 \times$ Openness $+0.113 \times$ Conscientious $+0.226 \times$ Extraversion $+\mu$

In model 2, ENT has a significant and negative correlation with PSY, while FAC and QUA show no connection at a statistical significance of 95\%. Regarding the student's demographic elements, including gender (SEX) and learning year (YEA), the year of learning appears to be irrelevant to the social-related behaviors; however, SEX has a significant and positive relationship with the psychosocial development of the students with the confidence level of $95 \%$. Remarkably, all of the personalities presented in the table significantly associate with PSY. In detail, PSY positively relates to Openness, Conscientious, and Extraversion, yet negatively correlates with Agreeable in teams of social practices. Particularly, Openness students are observed to achieve 0.331 out of 5 units higher than ones without this personality with respect to psychosocial skills. Similarly, Conscientious and Extraversion students seem to be better at dealing with interactive situations with 0.149 and 0.423 out of 5 units higher than those lacking these characters. Thus, model 2 can be written as below:

PSY Model: Model 2: PSY $=2.473-0.0580 \times$ ENT $+0.0995 \times$ SEX $+0.331 \times$ Openness $+0.149 \times$ Conscientious $0.0671 \times$ Agreeable $+0.423 \times$ Extraversion $+\mu$

Model 3 gives information about the development of students' health through the relationship between three school-related independent variables and the dependent variable about the overall health of students. There is a strong and positive association between QUA and HEA, whereas both FAC and ENT do not correlate with HEA at the confidence level of 95\%. Next are demographic factors; the result shows that male students are likely to have a better health status than females when the average coefficient of the male is 0.132 out of 5 higher than this figure of the female. Unlike the SEX variable, the connection between YEA and HEA is not significant at the 0.05 level. Noticeably, all personality variables significantly and positively impact on students' health since the coefficients of openness, conscientious, agreeable, and extraversion are positive and higher than 0.4. In particular, open students seem to get better health with 0.455 out of 5 units than ones with another characteristic. Similarly, conscientious, agreeable, and extraversion personalities have better health with $0.406,0.478,0.422$ out of 5 units, respectively, than those without these personalities. Therefore, model 3 can be written as below:

HEA model: Model 3: HEA $=2.636+0.104 \times Q U A+0.132 \times S E X+0.455 \times$ Openness $+0.406 \times$ Conscientious $+0.478 \times$ Agreeable $+0.422 \times$ Extraversion $+\mu$

The final column of Table 4 shows regression analysis results of Satisfaction variable in which we can see the correlation between the independent variables, including school facilities, teaching quality, and entertainment activities, and the dependent variable containing students' enjoyment in their universities. It's clear that QUA, ENT, and FAC variables significantly and positively impact on satisfaction variable. Regarding student demographic, gender (SEX) has no efficiency on students' satisfaction; however, learning year (YEA), which is on the reverse pattern, negatively affects satisfaction variable. Particularly, it can be said that the more learning years students take, the more dissatisfaction level students achieve. The fascinating point in regression analysis results of Satisfaction variable is that all four students' personalities, including open personality, conscientious personality, agreeable personality, and extraverted personality have statistical significance to satisfaction variable. In particular, students who are open, can achieve 0.131 points higher than those without this character. The same goes for the other three personalities that students with conscientious personality, agreeable personality, and extraverted personality get more satisfaction to their universities of $0.109,0.0936$ and 0.0512 out of 5 units, respectively. Hence, model 4 can be written as below:

Satisfaction Model: Model 4: SAT $=0.412+0.0506 \times F A C+0.0315 \times Q U A+0.0429 \times E N T-0.0139 \times Y E A+0.131 \times$ Openness $+0.109 \times$ Conscientious $+0.0936 \times$ Agreeable $+0.0512 \times$ Extraversion $+\mu$

\section{Conclusions}

To sum up, GPA or academic result is no longer the only one scale of students' comprehensive development, and students should be evaluated thoroughly through cognitive development, psychological development, and health development. Besides, this research has been carried out in Vietnam where there are many differences in education, school infrastructure and students' health status to developed countries where most of the investigations are conducted so that we might have a more general 
conception of the comprehensive development of the student. After doing the research, we conclude that student development is both positively and negatively impacted by school resources. Furthermore, besides those school factors, student personality and student demographics are also significant to the comprehensive development of students, which means that students who have the same school resources, do not have the same level of development. Therefore, it cannot be concluded that universities with the most excellent resources might do best in shaping students' comprehensive development. Although this research has acknowledged the importance of the findings, there are some limitations to the topic that should notice. This is because the sample was collected only at five universities in Vietnam with a limited number of observations, resulting in the representative of the study. Future research should collect data with a larger population from a more diverse set of universities to enhance the reliability and validity of the data. Besides, due to online data collection, the surveys did not control non-response bias. Students who did not respond to this questionnaire might be the ones who are dissatisfied with the learning environment, leading to some errors in the research results. As the study undertook during a specific period and no comparisons with past and future, the conclusion validity may be a topic of discussion.

\section{References}

Abbott, M., \& Doucouliagos, C. (2003). The efficiency of Australian universities: a data envelopment analysis. Economics of Education Review, 22(1), 89-97.

Agasisti, T., \& Zoido, P. (2019). The efficiency of schools in developing countries, analysed through PISA 2012 data. SocioEconomic Planning Sciences, 68, 100711.

AGR (2007). Available at: http://www.agr.org.uk/

Ahmad, I., \& Szpara, M. Y. (2005). Education for democratic citizenship and peace: Proposal for a cosmopolitan model: Educational studies. Journal of the American Educational Studies Association, 8-23.

Aljaaidis, K. S., Bagais, O. A. \& Al-Moataz, E. (2020). Knowledge sharing and individuals' effectiveness in educational institutions. Management Science Letters, 10(15), 3477-3484.

Appelbaum, P. S. (2006). Law \& psychiatry: “Depressed? get out!”: Dealing with suicidal students on college campuses. Psychiatric Services, 57(7), 914-916.

Bafadal, I. (2003). Management Series for Quality Improvement of School-based Education: Management of school equipment theory and its application. Jakarta: PT Bumi Aksara.

Banks, J. A. (2014). Diversity, group identity, and citizenship education in a global age. Journal of Education, 194(3), 1-12.

Bjorke, S. A. (2017). Higher Education impact on human development: A case study.

Bloom, B. S. (1956). Taxonomy of Educational Objectives. New York: David McKay Co Inc..

Chamorro-Premuzic, T., \& Furnham, A. (2003). Personality traits and academic examination performance. European Journal of Personality, 17(3), 237-250.

Chickering, A. W. \& Reisser, L. (1993). Education and Identity. San Francisco: Jossey-Bass.

Choi, N. (2005). Self-efficacy and self-concept as predictors of college students' academic performance. Psychology in the Schools, 42(2), 197-205..

Coleman, J. S. (1966). Washington and Welfare, et. al., Equality of Educational Opportunity, D. C.: United States Department of Health. Education.

Conard, M. A. (2006). Aptitude is not enough: How personality and behavior predict academic performance. Journal of

Research in Personality, 40(3), 339-346.

Cooper, H., Valentine, J. C., Nye, B., \& Lindsay, J. J. (1999). Relationships between five after-school activities and academic achievement. Journal of Educational Psychology, 91(2), 369.

Costa, P. \& Mccrae, R. (1992). NEO PI-R: Professional Manual: Revised NEO PI-R. Florida: Psychological Assessment Resources, Inc..

Duque, L. C., \& Weeks, J. R. (2010). Towards a model and methodology for assessing student learning outcomes and satisfaction. Quality Assurance in Education, 84-105.

Durán-Narucki, V. (2008). School building condition, school attendance, and academic achievement in New York City public schools: A mediation model. Journal of Environmental Psychology, 28(3), 278-286.

Earthman, G. (1996). Review of Research on the Relationship between School Buildings, Student Achievement, and Student Behavior.

Ewell, P. (2005). Alimni studies as instruments of public policy. s.1.:The US experience.

Gatten, J. N. (2004). Student psychosocial and cognitive development: theory to practice in academic libraries. Reference Services Review, 157-163.

Gudeva, L. K., Dimova, V., Daskalovska, N., \& Trajkova, F. (2012). Designing descriptors of learning outcomes for Higher Education qualification. Procedia-Social and Behavioral Sciences, 46, 1306-1311..

Guironnet, J. P., \& Peypoch, N. (2018). The geographical efficiency of education and research: The ranking of US universities. Socio-Economic Planning Sciences, 62, 44-55..

Hakimi, S., Hejazi, E. \& Lavasani, M. G. (2011). The relationships between personality traits and students' academic achievement. Procedia - Social and Behavioral Sciences, 836-845.

Hanushek, E. A., \& Woessmann, L. (2008). The role of cognitive skills in economic development. Journal of Economic Literature, 46(3), 607-68.

Harafsheh, I., Abu-eid, F., Alshorman, S., \& Kanaan, E. (2020). Barriers to physical activities of college students with disabilities. Management Science Letters, 10(14), 3339-3346. 
Harris, D. N., \& Sass, T. R. (2011). Teacher training, teacher quality and student achievement. Journal of Public Economics, 95(7-8), 798-812.

Hedges, L. V., \& Olkin, I. (1980). Vote-counting methods in research synthesis. Psychological Bulletin, 88(2), 359.

Idris, F., Hassan, Z., Ya'acob, A., Gill, S. K., \& Awal, N. A. M. (2012). The role of education in shaping youth's national identity. Procedia-Social and Behavioral Sciences, 59, 443-450..

John, J. (2009). Study on the nature of impact of soft skills training programme on the soft skills development of management students. Pacific Business Review, 19-27.

Kain, J., Leyton, B., Concha, F., Close, M., Soto-Sánchez, J., \& Salazar, G. (2017). Preschool children's physical activity intensity during school time: Influence of school schedule. Preventive Medicine Reports, 8, 6-9.

Kaplan, L. S., \& Owings, W. A. (2001). Teacher quality and student achievement: Recommendations for principals. NASSP Bulletin, 85(628), 64-73.

Katula, R. A., \& Threnhauser, E. (1999). Experiential education in the undergraduate curriculum. Communication Education, 48(3), 238-255.

Kim, J., Kwon, Y., \& Cho, D. (2011). Investigating factors that influence social presence and learning outcomes in distance higher education. Computers \& Education, 57(2), 1512-1520..

Kirjavainen, T. (2009). Essays on the Efficiency of Schools and Student Achievement. Helsinki: Helsinki School of Economics.

Kohlberg, L. (1958). The Development of Modes of Thinking and Choices in Years 10 to 16. s.1.:University of Chicago.

Komarraju, M., Karau, S. J., Schmeck, R. R., \& Avdic, A. (2011). The Big Five personality traits, learning styles, and academic achievement. Personality and Individual Differences, 51(4), 472-477.

de Koning, B. B., Loyens, S. M., Rikers, R. M., Smeets, G., \& van der Molen, H. T. (2012). Generation Psy: Student characteristics and academic achievement in a three-year problem-based learning bachelor program. Learning and Individual Differences, 22(3), 313-323.

Kuh, G. D., Kinzie, J. L., Buckley, J. A., Bridges, B. K., \& Hayek, J. C. (2006). What matters to student success: A review of the literature (Vol. 8). Washington, DC: National Postsecondary Education Cooperative.

Leeming, F. C., Porter, B. E., Dwyer, W. O., Cobern, M. K., \& Oliver, D. P. (1997). Effects of participation in class activities on children's environmental attitudes and knowledge. The Journal of Environmental Education, 28(2), 33-42.

Lonska, J., \& Mietule, I. (2015). The impact of human capital development on the economic and social development of a country: empirical study. In proceedings of the 10th international scientific and practical conference (Vol. 2, p. 180).

Nusche, D. (2008). Assessment of learning outcomes in higher education: A comparative review of selected practices..

Palmer, S. \& Torgerson, D. J. (1999). Definitions of efficiency. Education and Debate, 318(7191), 1136.

Parker, J. D., Summerfeldt, L. J., Hogan, M. J., \& Majeski, S. A. (2004). Emotional intelligence and academic success: Examining the transition from high school to university. Personality and Individual Differences, 36(1), 163-172.

Phuc, P., Vinh, N., \& Do, Q. (2020). The implementation of outcome-based education: Evidence from master program in economic management at Hanoi universities. Management Science Letters, 10(14), 3299-3306.

Podinovski, V. V., Ismail, I., Bouzdine-Chameeva, T., \& Zhang, W. (2014). Combining the assumptions of variable and constant returns to scale in the efficiency evaluation of secondary schools. European Journal of Operational Research, 239(2), 504-513.

Porter, J. (2007). B-Schools Soft on 'Soft Skills'.

Posner, G. (1992). Analyzing the Curriculum. USA: McGraw-Hill.

Queiroz, M. V. A. B., Sampaio, R. M. B., \& Sampaio, L. M. B. (2020). Dynamic efficiency of primary education in Brazil: Socioeconomic and infrastructure influence on school performance. Socio-Economic Planning Sciences, 70, 100738.

Rynes, S. L., Trank, C. Q., Lawson, A. M., \& Ilies, R. (2003). Behavioral coursework in business education: Growing evidence of a legitimacy crisis. Academy of Management Learning \& Education, 2(3), 269-283.

Sandeen, A. (1991). The Chief Student Affairs Officer: Leader, Manager, Mediator, Educator. Jossey Bass Inc., 350 Sansome Street, San Francisco, CA 94104-1310.

Sanders, A. E., \& Lushington, K. (2002). Effect of perceived stress on student performance in dental school. Journal of dental education, 66(1), 75-81.

Stronge, J. H., Ward, T. J., Tucker, P. D., \& Hindman, J. L. (2007). What is the relationship between teacher quality and student achievement? An exploratory study. Journal of Personnel Evaluation in Education, 20(3-4), 165-184.

Vanwynsberghe, G., Vanlaar, G., Van Damme, J., \& De Fraine, B. (2017). Long-term effects of primary schools on noncognitive outcomes of students at age 17. Studies in Educational Evaluation, 55, 83-93.

Vasileva-Stojanovska, T., Malinovski, T., Vasileva, M., Jovevski, D., \& Trajkovik, V. (2015). Impact of satisfaction, personality and learning style on educational outcomes in a blended learning environment. Learning and Individual Differences, 38, 127-135.

Walker, M. (2008). Working with College Students and Student Development Theory Primer. s.1.: s.n.

Wechsler, H., Devereaux, R. S., Davis, M., \& Collins, J. (2000). Using the school environment to promote physical activity and healthy eating. Preventive Medicine, 31(2), S121-S137.

Wilks, C. R., Auerbach, R. P., Alonso, J., Benjet, C., Bruffaerts, R., Cuijpers, P., ... \& Sadikova, E. (2020). The importance of physical and mental health in explaining health-related academic role impairment among college students. Journal of Psychiatric Research, 123, 54-61.

Zee, M., Koomen, H. M., \& Van der Veen, I. (2013). Student-teacher relationship quality and academic adjustment in upper elementary school: The role of student personality. Journal of School Psychology, 51(4), 517-533. 
(C) 2020 by the authors; licensee Growing Science, Canada. This is an open access article distributed under the terms and conditions of the Creative Commons Attribution (CC-BY) license (http://creativecommons.org/licenses/by/4.0/). 